\title{
A Review of Gender and Full-Range Leadership Research and Suggestions for Future Research
}

\author{
Kelli K. Smith \\ Assistant Director \\ Career Services \\ University of Nebraska-Lincoln \\ Lincoln NE 68588-0451 \\ ksmith4@unl.edu \\ Gina S. Matkin \\ Assistant Director \\ Nebraska Union \\ University of Nebraska-Lincoln \\ Lincoln NE 68588-0452 \\ gmatkin1@unl.edu \\ Susan M. Fritz \\ Head and Professor \\ Department of Agricultural Leadership, Education and Communication \\ University of Nebraska-Lincoln \\ Lincoln NE 68583-0709 \\ smfritz1@unl.edu
}

\begin{abstract}
In this paper the research on gender and Full-Range Leadership is documented and explored. Included is consideration of research that studied Full-Range Leadership directly as well as indirect study that contributed to the field of research on Full-Range Leadership. The paper culminates in a series of recommendations for future research. It is hoped that these will help to move the field from documenting the differences or similarities of leadership (or perceptions of leadership) between women and men, to studying why these differences might exist. Additional recommendations are included that will help transport the value of this research from the pages of scholarly journals into organizations, communities, and the workplace.
\end{abstract}

\section{Introduction}

Gender and leadership is a much-researched area with many unanswered questions. For example, studies that explore the origin behind the conflicting findings on gender and leadership are nearly absent. A full understanding of the 
current and historical research is needed in order for this effort to achieve its purpose. Thus, this paper begins with an explanation of the Full Range Leadership Model including the Multifactor Leadership Questionnaire (MLQ). In addition, a documentation of the progression of the literature on gender and Full-Range Leadership is included in this paper.

This research can be divided into three main subject areas: early research, workplace issues, and future research (see Figure 1 below). While these areas are not "time-bound," they represent significant bodies of research that can be studied alone or in combination with other areas. This division of research enables a better understanding and interpretation of the wealth of information that exists on gender and Full-Range Leadership. For example, early research findings that do not mention Full-Range Leadership explicitly provide an important foundation for future work. These are explored and followed by a discussion of the research that specifically examines stereotypes and gender roles and how these impact the role of women as leaders.

The second major area, workplace issues, includes leader effectiveness, satisfaction with leaders, and leader evaluations as they relate to Full-Range Leadership. Contextual variables that might lead to a better understanding of the often-conflicting findings are then discussed. The findings in this area lead to a call for more research that incorporates contextual variables into the research design.

This leads to the third major area, future research, culminating in a discussion of what is not known about gender and leadership. Recommendations for future research are included. 
Figure 1. Overview of major areas of research on gender and full-range leadership

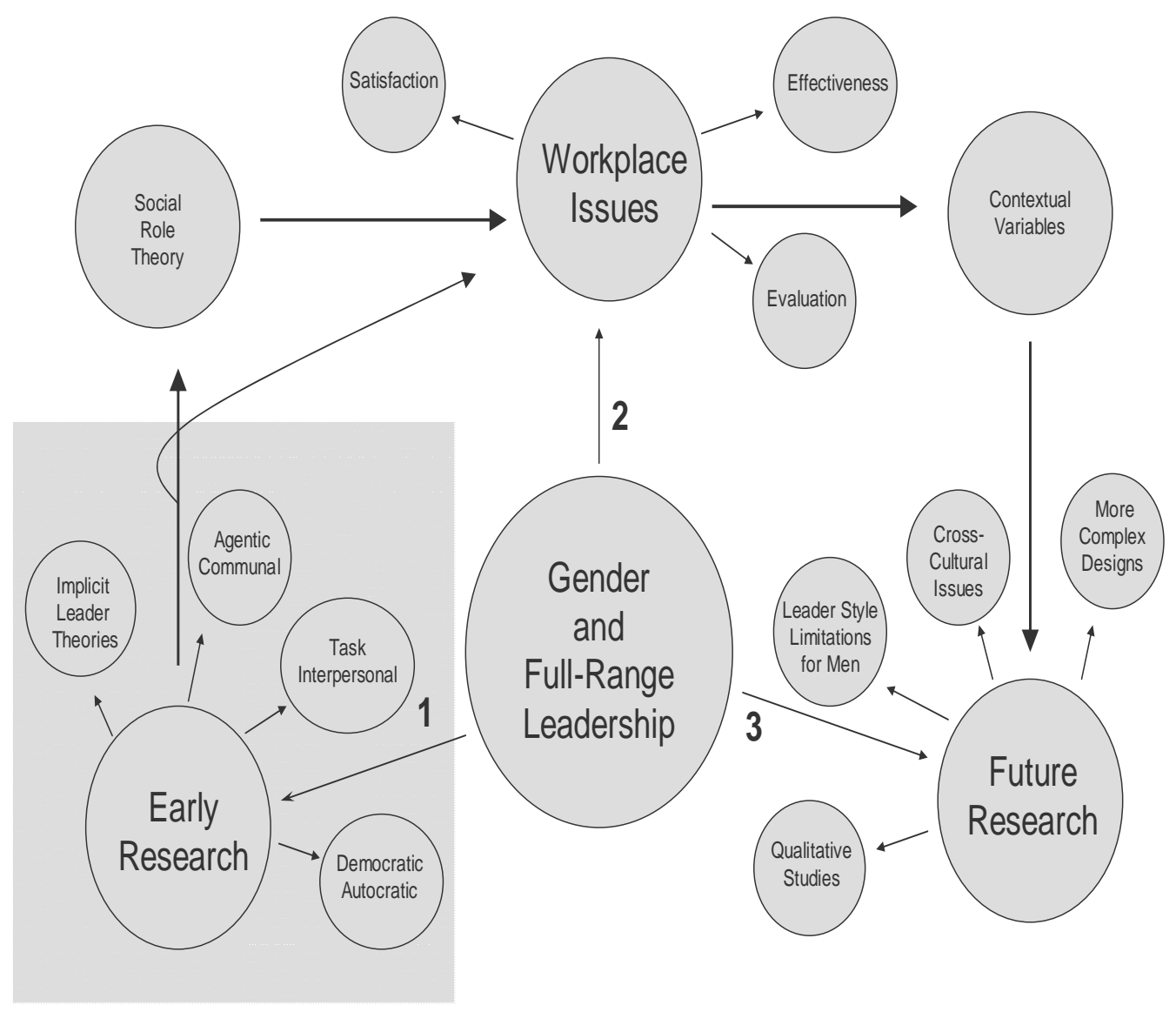

\section{Overview of Full Range Leadership}

Bass' (1985) theory of Transformational Leadership posits that leadership goes beyond exchanging rewards for desired performance by developing, intellectually stimulating, and inspiring followers to transcend their own self-interests for a higher purpose, mission or vision. His theory was developed from Burns’ (1978) classification of transforming and transactional leadership. Burns contended that transactional leadership "occurs when one person takes the initiative in making contact with others for the purpose of an exchange of valued things," while transforming leadership "occurs when one or more persons engage with others in such a way that leaders and followers raise one another to higher levels of motivation and morality” (p. 101). Unlike Burns, Bass did not consider transformational and transactional leadership to be opposite ends of a continuum and posed that leaders can display both leadership behaviors.

Bass and Avolio (1994a) later proposed the Full-Range Leadership Model. This model suggests that transformational and transactional leadership behaviors can optimize organizational effectiveness when demonstrated appropriately and at the 
desired frequency, resulting in transformation through higher-order change. Transactional leadership is focused on motivating followers by exchanging rewards for performance of job expectations. It is a fundamental leadership practice in which a leader identifies roles, expectations, and performance parameters, and guides followers to desired results. In contrast, a transformational leader interacts with followers in ways that stimulate their thinking, inspire their performance, and result in performances beyond expectations. Transformational leaders attempt to radically influence the viewpoint of followers about their perception of what is important about their jobs. Followers are encouraged to rethink the context in which work is accomplished and their role as contributors to the organization's accomplishments. As a result, transformational leadership can result in performance and development beyond expectations, and can help organizations achieve fundamental or higher-order change.

\section{Multifactor Leadership Questionnaire}

Bass and Avolio (1990) have, in addition to identifying the elements of transactional and transformational leadership, provided a validated instrument called the Multifactor Leadership Questionnaire (MLQ) to measure the full range of leadership. The first set of leadership behaviors in the Full-Range Leadership Model identifies four distinct transformational leadership behaviors, called the four "I's." These are idealized influence, inspirational motivation, intellectual stimulation, and individualized consideration. Transactional leadership is described by the following three behaviors: contingent reward, active management-by-exception (MBE-Active), and passive management-by-exception (MBE-Passive). Laissez-faire leadership is the last behavior defined and is considered to be the lack of leadership. It is the most inactive behavior. The leader chooses not to guide performance when the situation would warrant. This leader behavior would not be classified as transformational or transactional.

Transformational leadership behaviors and contingent reward, a constructive transactional behavior, have proven to be significantly and positively related to effective leadership, including the outcomes of willingness of followers to exert extra effort, leadership effectiveness, and an overall sense of satisfaction with the leader on the part of followers. MBE-Active has been shown to have either slightly positive or neutral correlations to outcomes. MBE-Passive and Laissezfaire leadership behaviors have been found in most studies to be negatively correlated with follower outcomes and are, therefore, considered to be the least active and constructive behaviors.

\section{Early Research Linking Gender and Leadership Style}

Early studies on gender and leadership, while not specifically mentioning transformational or transactional leadership, have contributed greatly to much of the transformational research literature. 
It is important to explore what may be considered to be a "historical context" for the study of gender and transformational leadership. Therefore, this section documents some of the early research as well as the studies of stereotypes, gender roles, and Social Role Theory.

\section{Implicit Leadership Theories}

Research in the area of gender stereotypes and transformational leadership can be viewed through the lens of implicit leadership theories (ILTs). Implicit Theory suggests that one's idea of what effective leadership is has a large impact on leadership ratings, and as a result, leadership questionnaires often yield biased ratings of leadership behavior (Rush, Thomas, \& Lord, 1977). Little is known about how women and men differ in their expectations of effective leader behaviors, and researchers must be cautious not to assume that all women and men hold the same view of effective leadership by only focusing on betweengender effects (how women and men differ). Yet there may be some merit in exploring whether there are general tendencies for women and men to share ILTs. In a study conducted by Russell, Rush, and Herd (1988) that examined women's behavioral expectations of effective male and female leaders, it was found that many similarities existed among the female participants in their views of effective leadership. While there were age-related differences among the women in their expectations, particularly with regard to effective female leadership, the results suggested that women, irrespective of age, expected that a female leader should exhibit higher levels of consideration - a stereotypic female leader behavior than a male leader.

It is possible that, in general, female and male followers have different ILTs of transformational and transactional leadership for male and female leaders. Maher's (1997) study examined gender-related stereotypes. She suggested that men may have similar ILTs for male and female leaders, but women may have different ILTs for both genders. Further, female leaders attributed their use of relational styles to their transformational leadership whereas men felt that their power and direct styles contributed to transformational leadership (Komives, 1991b). This may suggest that women have ILTs of transformational leadership that include more developmental and nurturing behaviors than men.

\section{Gender and Leader Style}

The examination of gender's impact on leadership style is another area that has been widely researched. Much of this research was conducted on the more common distinction between task-oriented styles (or initiation of structure) and interpersonally-oriented styles (also labeled consideration), and the dimensions of democratic versus autocratic (similar to the dimensions of participative and directive). Previously, Eagly and Johnson (1990) conducted a meta-analysis of gender and leadership style that examined studies comparing men and women on task and interpersonal styles as well as democratic and autocratic styles. Evidence 
was found for both the presence and absence of differences between men and women. While the authors concluded that the overall search for sex differences in leader style was not demonstrated, significant gender differences were reported in the use of democratic or participatory styles of leadership. Their research revealed that women leaders are less directive than men. Eagly, Makhijani, and Klonsky (1992) later demonstrated that women are viewed less favorably when leading in a direct manner; however, women tend to adopt a direct style less frequently than men (Eagly, Johannesen-Schmidt, \& van Engen, 2003).

\section{Social Role Theory}

\section{Gender Stereotypes}

Considerable research has been conducted on gender stereotypes in the leadership domain. Regardless of the number of men or women that match the masculine or feminine stereotype, these stereotypes have a significant influence on how potential performance of male and female leaders is perceived by followers.

There is a significant amount of research specifically examining whether there are different stereotypes for male and female leaders exhibiting more traditional styles of leadership such as initiating structure and consideration. In general, studies "have continued to show that the 'agentic' stereotypic male qualities (e.g., competitiveness, daring, assertiveness) are more aligned with stereotypic views of managerial roles, versus 'communal' stereotypic female qualities (of kindness, supportiveness, and affection)" (Vecchio, 2002, p. 652). A specific study in a military context found men were believed to possess the motivation and leadership qualities necessary for effective performance more than women, and women were believed to possess more feminine attributes that impair effective military performance (Boldry, Wood, \& Kashy, 2001). However, men and women did not differ on objective measures of actual performance; therefore, the authors argued that gender stereotypes negatively influenced cadets' evaluations of their female classmates. A meta-analysis by Eagly, et al. (1992) found female leaders were evaluated slightly more negatively than male leaders in studies in which differences could only be due to the subjects' stereotypes or biases of leaders.

Russell et al. (1988) also researched the stereotypes of consideration and initiating structure styles for men and women who are leaders. They found that when female subjects were asked to describe characteristics of effective male and effective female leaders, female leaders were rated higher in consideration and structure. Couple this finding with the assertion that female leaders may be in a “double-bind” when exhibiting stereotypical masculine (leadership) behaviors (Kolb, 1999). In addition, she cites several studies that find that emulation of masculine leadership behaviors by women can have a negative effect on evaluation of them as leaders. A double-bind that is particularly troublesome for women leaders is what Jamieson (1995) calls the feminine/competency bind, where acting "feminine" is associated with incompetence and acting "competent" 
is associated with masculinity. This can only lead to the conclusion that is it "unfeminine” to be competent (Oakley, 2000).

Eagly and Karau (2002) suggest that there is a perceived incongruity between the female gender role and typical leader role. They posit that this incongruity creates prejudice towards female leaders. Eagly (1987) discusses "Social Role Theory" as a means to better understand how gender roles (consensual beliefs about the attributes of women and men) and social roles (socially shared expectations that apply to persons who occupy a certain social position or are members of a particular social category) interact to produce sex differences in social behavior. Applied to leadership, this theory says that leaders occupy roles defined by their specific positions in a hierarchy and simultaneously function under the constraints of their gender roles (Eagly, et al., 2003).

\section{Gender Stereotypes and Full-Range Leadership}

Unlike the long-established styles of consideration and initiating structure, transformational leadership may provide a way that male and female leaders can integrate gender role and social role demands, thereby transcending gender role stereotypes. While researchers have suggested that stereotypes can explain their findings of differences between women and men on transformational and transactional leadership (Druskat, 1994; Bass \& Avolio, 1994b), very little research exists that directly examines this possibility. Utilizing a modified MLQ form, Maher (1997) conducted one of the few studies explicitly examining the relationship between gender stereotypes of transformational and transactional leadership and ratings of actual managers on these styles of leadership. While she found no significant differences between actual male and female leaders on transformational or transactional leadership, she did find significant differences in how female subjects viewed hypothetical male and female leaders. Female stereotypic leaders were evaluated as exhibiting more transformational and transactional behaviors and fewer laissez-faire behaviors than male stereotypic leaders. Rosener (1990) conducted a survey of female and male leaders seeking descriptions of their leadership approach. Using the MLQ, she found significant differences with respect to the use of transformational behaviors. Women scored higher (except for intellectual stimulation which showed no significant difference) on transformational leadership behaviors. A possible reason for the lack of gender differences in previous research may have been because leadership instruments before the MLQ measured mainly transformational aspects of leadership (AlimoMetcalfe, 1994; Eagly \& Johnson, 1990). In another study Hackman, Furniss, Hills, and Paterson (1992) also found, with the exception of intellectual stimulation, strong correlations between perceived feminine characteristics and transformational leadership behaviors.

Research demonstrates there are stereotype differences for female and male leaders, often to the detriment of women particularly when men serve as the evaluators (Eagly, et al., 1992). However, a recent meta-analysis conducted by 
Eagly, et al. (2003) shows women to be more transformational than men, suggesting that stereotypes associated with transformational leadership may be less negatively biased against women leaders than stereotypes associated with other leadership styles. Additionally, women may favor a transformational leader style because it provides them "with a means of overcoming the dilemma of role incongruity-namely, that conforming to their gender role can impede their ability to meet the requirements of their leader role” (Eagly et al., 2003, pg. 573). As Vecchio (2002) candidly states, while research in the area of stereotypes is intriguing, it is limited due to the typical omission of contextual dimensions.

\section{Workplace Issues}

\section{Effectiveness of Leaders}

In reviewing the literature on gender and Full Range Leadership, an important issue that emerged was leader effectiveness. Transformational leadership, along with the use of contingent reward, is a style significantly related to effectiveness as previously mentioned (Bass, 1985, 1997, 1998; Center for Leadership Studies, 2003; DeGroot, Kiker, \& Cross, 2000; Lowe, Kroeck, \& Sivasubramaniam, 1996). Following is a review of the literature that addresses the issue of gender differences and leader effectiveness.

Eagly, et al. (1992) reviewed studies on gender and the evaluation of leaders using transformational leadership as the model. Research over 10 years was analyzed. The authors concluded that there was evidence of a slight tendency for females and males to differ in their evaluations. The difference was somewhat greater when leaders were male and occupied male-dominated roles, therefore, strongly influenced by context. In a further meta-analytic study, Eagly, Karau, and Makhijani (1995) reviewed studies that tested whether student demographics (age, education level, and gender) correlated with perceptions of professors' leadership styles. Aggregated data found no evidence of a sex effect for effectiveness, yet men were perceived as more effective than women in roles that were defined in masculine terms and women were more effective than men in roles that were defined in less masculine terms. Both male and females viewed professors as transformational, but male participants viewed their professors as more transactional than female participants.

It is important to note that the research methods by Eagly et al. $(1992,1995)$ are not without criticism. For example, Vechhio (2002) points out that 12 studies were removed from the Eagly et al. (1995) study because they were relative outliers (reduced the homogeneity statistic by the largest amount), but all of the effect sizes from the 12 favored male leaders over female leaders. The removal of these 12 studies resulted in an overall effect size that slightly favored female leaders over male leaders. Additionally, effectiveness, as measured by the MLQ is a measure of leader and follower ratings of effectiveness and not actual organizational indicators of leader effectiveness. 
The recent meta-analysis conducted by Eagly et al. (2003) shows women to be slightly more transformational than men. Results showed that men, on the other hand, were slightly more likely to manifest the lesser effective transactional and laissez-faire leadership behaviors. While the differences between men and women were small, "the data attest to the ability of women to perform well in leadership roles in contemporary organizations” (Eagly et al., 2003, p. 32).

\section{Evaluation of and Satisfaction with Leaders}

In their 1992 meta-analysis, Eagly, et al. reviewed the research on 61 studies of gender and the evaluation of leaders. In general, they found that evaluations for women leaders were less favorable than those for men. Additionally, they found that the tendency to favor men was more pronounced when the dependent variable was the leader's competence or the subject's satisfaction with the leader rather than perceptions of leader style. Moreover, the model for the specific leadership style used as a dependent variable indicated that measures that did not assess specific leadership style produced a stronger bias in favor of male leaders than those style measures that assessed interpersonal orientation. Autocratic style produced significantly more favorable evaluations of male leaders than did other portrayals that did not include style information. Women's leadership was perceived to be more task-oriented than equivalent behaviors by men. This may reflect a tendency to contrast women's leadership behavior from the female stereotype and, therefore, view this behavior as more extreme. Conversely, men leading in a more "feminine" (communal) manner did not create a disadvantage for men relative to women. Thus, it appears that, all other things being equal, men may have greater freedom than women to lead in a range of styles without encountering negative reactions.

\section{Contextual Variables}

\section{Gender Composition in the Workplace}

Gardiner and Tiggemann (1999) examined the impact of gender composition of the organization on gender differences in leader behavior when they studied an equal number of male and female managers in several male-dominated and female-dominated industries. In female-dominated industries (e.g., nursing, early childhood education) women were more people-oriented. They were more taskoriented in male-dominated industries (e.g., accounting, timber industry, and academia). However, it has been argued that with such a large variety of contexts, their results may be confounded with other organizational contextual variables such as organizational structure and mission (van Engen, van der Leeden, \& Willemsen, 2001).

Research by Eagly, et al. (1995) showed support for gender composition as a contextual variable that moderates leader behavior. In their study, male and female leaders were found to be equally effective but men were found to be more 
effective than women in situations in which both leader and follower roles were numerically dominated by men, as well as in roles that were defined in stereotypical masculine terms. An earlier meta-analysis also found the extent to which leadership roles were male-dominated numerically related to sex differences in leadership style (Eagly \& Johnson, 1990). The tendency for female leaders to be more interpersonally oriented and more democratic than male leaders lessened the more the role they held was male-dominated.

In the strongly male-dominated military setting studied by Boldry, et al. (2001), both male and female cadets perceived males to have more leadership ability. The females were perceived to have more character than the other sex. Yet cadets' success in the corps was best predicted by perceived leadership ability, not character.

In their meta-analysis of gender and the evaluation of leaders, Eagly, et al. (1992) found that the devaluation of female leaders was greater when leaders occupied male-dominated roles than for roles occupied equally by both sexes, and it was also greater when the evaluators were men. The authors concluded these findings suggest women "pay a price" if they occupy traditionally male-dominated leadership positions. Negative evaluation of women may still exist in predominantly male organizational cultures (Eagly, et al., 1992). This may be the result of women attempting to use traditionally male leadership styles to adapt or "fit into" the male-dominated workplace.

\section{Type of Organization}

The research on the extent to which transformational and transactional leadership behavior of male and female leaders is influenced by organizational type is decidedly mixed. Within a corporate setting, Carless (1998) found that though supervisors of female leaders rated them higher on five of the seven transformational behaviors than males, followers of leaders in the corporate environment of banking did not agree there was any difference between the transformational behaviors of male and female leaders. According to van Engen, et al. (2001), there were no gender differences in leadership styles, including transformational leadership behaviors, among large department store managers. Maher (1997) also found that employees are likely to evaluate their male and female managers as equally transformational. In this study, college students attributed gender-stereotypic behaviors to hypothetical female and male leaders, but saw no differences in either transformational or transactional leadership between their real male and female managers.

A study comparing self- and observer-rated transformational leadership behaviors of male and female leaders in a large U.S. social services agency found no significant differences in transformational leadership between males and females at comparable levels (Manning, 2002). Other researchers (Komives, 1991a; Davidson, 1996) discovered no transformational leadership gender differences 
within higher education as well. The two studies examined the self-perceptions of transformational leadership among males and females in higher education settings. Combined with the previously described studies, this may indicate that transformational leadership is at least as effective for female as for male leaders.

Some studies in educational and other settings, however, found that followers perceive their female leaders as more transformational than male leaders (McGrattan, 1997; McHugh, 1999). In a meta-analysis of 49 studies, Eagly, et al. (2003) found their categories of "educational” and "other" settings (healthcare, sports) produced the largest differences in the female direction on transformational, and "business" and "mixed" settings produced the smallest differences. Within yet another organizational context, Druskat (1994) examined the evaluations of female leaders in all-female Catholic religious orders and the evaluations of male leaders in all-male Catholic religious orders. While both sets of leaders were rated as transformational, female leaders were evaluated as being more transformational by female subordinates than male leaders who were evaluated by male subordinates.

\section{Summary and Recommendations}

This paper documents the study of gender and Full-Range Leadership. The literature in this area is vast. Future comprehensive research should include other influences and variables that could impact the interaction and interpretation of gender and leadership.

\section{Rater Direction}

For example, how do gender and organizational level interact to influence evaluations of transformational leadership behavior? This is an important area of research but relatively absent in the literature. Manning (2002) conducted one of the only studies with this as a focus. While no differences were found in transformational leadership between male and female leaders at equivalent levels, the research did show that raters viewed top managers of both genders as less transformational than average for the sample and those at lower levels as more transformational than average.

Interestingly, Manning (2002) also found that the self-ratings of those two groups were opposite of those of the subordinate raters, suggesting that rater direction is another critical component in the study of gender and transformational leadership. There is some evidence to suggest that it is important to take into account rating source when researching gender differences (Eagly \& Johnson, 1990), yet very few studies exist on gender differences of transformational leadership as measured from multiple perspectives. One study found that superior and selfratings evaluated female managers as more transformational than males, while subordinates evaluated male and female leaders equally transformational (Carless, 1998). 


\section{Cross-Cultural Issues}

Another area of interest involves examining the role of cross-cultural implicit transformational leadership theories for male and female leaders. For example, Schein's (2001) review found that men are perceived to be more qualified as managers than women especially by men, across several countries. Coupled with Bass' (1997) contention that transformational leadership is universally applicable, regardless of culture, this raises the question of gender differences in transformational leadership across cultures. Examining the role that ILTs play in evaluating transformational leadership in male and female leaders, particularly across cultures, may prove a rich area of study.

\section{Qualitative Studies}

While a great deal of research exists that helps to quantify the differences between leadership styles of women and men, perceptions of women and men as leaders and countless other variables as they relate to gender and leadership, very little evidence exists that helps us to answer the questions about why these differences exist and how individual leaders are affected by them. Research journals tend to favor a quantitative approach; however, it seems apparent that the questions posed cannot be completely answered in this manner. With the vast body of data available, the time may be right for a different approach. This approach could focus on theory building, case studies, in-depth explorations (biographies) of effective female leaders as well as other qualitative approaches. While perhaps not as generalizable, these accounts could provide insights, as well as data charged with meaning to help us learn how to put the past research to better use and inform the field on future directions for quantitative work.

\section{Limitations for Males}

Research has demonstrated evaluation of and satisfaction with women leaders is more negative than males in predominantly male organizations (Eagly, et al., 1992). However, very few studies have examined the effect for men who lead in traditionally feminine ways or within predominantly female organizational cultures. Whether such male leaders would be more, less or equally effective as female leaders in either situation is an area needing further study.

\section{Recommendations for Practice}

Research on leadership theory is vital to understanding leader roles and workplace issues; yet, it is meaningless without some application to organizations, communities, and the workplace. It is proposed here that this lack of application is one of the reasons that the vast research on gender and leadership has not produced a meaningful shift in the biased interpretations of leadership styles of men and women. Numerous leadership development models exist that are utilized in the workplace. Are these models based on male-defined theories of leadership? 
Are they equally effective in developing male and female leaders or are they biased somehow? The answers to these questions are absent from the literature. Seeking these answers may help us to bring some of the past research findings "to life" and allow us to begin to create the changes that are called for in the pages of the academic journals.

A good leadership development program may be thought of from two perspectives: the organizational and the individual (London, 2002). At the individual level, there must be an assessment of the leader's (or potential leader's) talents and a way of determining areas that need further development. The organization then provides the resources to enable one's individual development as well as support for the ongoing development of leaders. According to London, the following components comprise an integrated program at individual and organizational levels:

- Corporate needs analysis.

- Overall assessment of talent at different organizational levels.

- Skill gap analysis.

- Early identification of talent.

- Development planning.

- Support for development.

- $\quad$ Ongoing assessment and development.

While this can be viewed as a thorough and comprehensive approach, it seems lacking and possibly counterproductive if not combined with a thorough understanding of the added dimension of the effects of gender and gender stereotypes on the development of leaders. For example, if an organization adopts a leadership program but ignores the different expectations that followers may have for male and female leaders, they may be setting some leaders up for failure while supporting others.

The authors believe organizations must consider several factors before implementing a leadership development program. Based on the findings found in exploring the literature on gender and leadership, the following steps are proposed to help organizations support leadership in both women and men:

- An analysis of the organizational culture for evidence of covert or overt gender bias.

- An exploration of the leadership paradigm to determine if it is equally effective for male and female leaders.

- Formal programs that provide support for both female and male leaders (e.g. mentoring programs).

- An examination of support systems for male and female leaders for subtle gender biases.

- Examination of organizational policies and benefits for presence of absence of particular policies that affect female leaders (e.g., child care, maternity leave, flexible working schedules). 
Considering the impact or potential impact of each of these could help organizations to ensure that both male and female leaders are receiving the maximum benefit and support from the organization. In addition to benefiting leaders, this could also benefit organizations by maximizing the leadership potential of all leaders.

\section{Conclusion}

Research on gender and Full Range Leadership is not lacking in the literature. Countless studies as well as a recent meta-analysis (Eagly et al., 2003) exist. While it may seem that the publication of yet another document on the subject is, at best, redundant, it is hoped that this article can help foster research that goes beyond the surface and explores the reasons behind the recurrent and sometimes contradictory findings.

Suggestions for further research include examination of rater direction, examination of the interaction of cross-cultural issues, exploration of the causes behind the findings, and the limitations for men that lead in traditionally feminine ways or within predominantly female organizational cultures. Practical applications include examining organizational norms and policies for gender bias as well as developing programs to support the leadership development of both women and men.

Women and men must be valued equally for their unique contributions, seen not as competitors, but rather as complementary to the success of the workplace or organization. Until then, communities, organizations, and workplaces will not be tapping into the full leadership potential that exists.

\section{References}

Alimo-Metcalfe, B. (1994). Gender bias in the assessment of women in management. In M. J. Davidson \& R. Burke (Eds.) Women in management: Current research issues. London: Wiley.

Bass, B. M. (1985). Leadership and performance beyond expectations. New York: The Free Press.

Bass, B. M. (1997). Does the transactional-transformational leadership paradigm transcend organizational and national boundaries? American Psychologist, 52, 130-139.

Bass, B. M. (1998). Transformational leadership: Industry, military, and educational impact. Mahwah, NJ: Erlbaum. 
Bass, B. M., \& Avolio, B. J. (1990). Transformational leadership development: Manual for the Multifactor Leadership Questionnaire. Palo Alto, CA: Consulting Psychologist Press.

Bass, B. M., \& Avolio, B. J. (Eds.). (1994a). Improving organizational effectiveness through transformational leadership. Thousand Oaks, CA: Sage Publications, Inc.

Bass, B. M., \& Avolio, B. J. (1994b). Shatter the glass ceiling: Women may make better managers. Human Resource Management Quarterly, 33(4), 549-560. Burns, J. M. (1978). Leadership. New York: Harper \& Row.

Boldry, J., Wood, W., \& Kashy, D. A. (2001). Gender stereotypes and the evaluation of men and women in military training. Journal of Social Issues, 57(4), 689-705.

Carless, S. A. (1998). Gender differences in transformational leadership: An examination of superior, leader, and subordinate perspectives. Sex Roles, 39, 887902.

Center for Leadership Studies (2003). Multifactor Leadership Questionnaire: Norms. Retrieved March 9, 2003, from http://cls.binghamton.edu/mlq.htm Davidson, B. J. (1996). Leadership styles of successful male and female choral directors. Unpublished doctoral dissertation, Arizona State University, Tempe, AZ.

DeGroot, T., Kiker, D. S., \& Cross, T. C. (2000). A meta-analysis to review organizational outcomes related to charismatic leadership. Canadian Journal of Administrative Sciences, 17, 356-371.

Druskat, V. U. (1994). Gender and leadership style: Transformational and transactional leadership in the Roman Catholic Church. Leadership Quarterly, 5, 99-119.

Eagly, A. H. (1987). Sex differences in social behavior: A social-role interpretation. Hillsdale, NJ: Lawrence Erlbaum, Associates, Inc.

Eagly A. H., Johannesen-Schmidt, M. C., \& van Engen, M. L. (2003). Transformational, transactional, and laissez-faire leadership styles: A metaanalysis comparing women and men. Psychological Bulletin, 129(4), 569-591.

Eagly, A. H., \& Johnson, B. T. (1990). Gender and leadership style: A metaanalysis. Psychological Bulletin, 108, 233-256.

Eagly, A. H., \& Karau, S. J. (2002). Role congruity theory of prejudice toward female leaders. Psychological Review, 109(3), 573-597. 
Eagly, A. H., Karau, S. J., \& Makhijani, M. G. (1995). Gender and the effectiveness of leaders: A meta-analysis. Psychological Bulletin, 117, 125-145.

Eagly, A. H., Makhijani, M. G., \& Klonsky, B. G. (1992). Gender and the evaluation of leaders: A meta-analysis. Psychological Bulletin, 111, 3-22.

Gardiner, M., \& Tiggemann, M. (1999). Gender differences in leadership style, job stress, and mental health in male-and female-dominated industries. Journal of Occupational and Organizational Psychology, 72, 301-315.

Hackman, M. Z., Furniss, A. H., Hills, M. J., \& Paterson, T. J. (1992). Perceptions of gender-role characteristics and transformational and transactional leadership behaviours. Perceptual and Motor Skills, 75, 311-319.

Jamieson, K. H. (1995). Beyond the double bind: Women and leadership. Oxford University Press: New York, N.Y.

Kolb, J. A. (1999). The effect of gender role, attitude toward leadership, and selfconfidence on leader emergence: Implications for leadership development. Human Resource Development Quarterly, 10(4), 305-320.

Komives, S. R. (1991a). Gender differences in the relationship of hall directors' transformational and transactional leadership and achieving styles. Journal of College Student Development, 32, 155-165.

Komives, S. R. (1991b). The relationship of same- and cross-gender work pairs to staff performance and supervisor leadership in residence hall units. Sex Roles, 24, 355-363.

London, M. (2002). Leadership Development. Lawrence Erlbaum Associates, Inc. Mahwah, NJ.

Lowe, K. B., Kroeck, K.G., \& Sivasubramaniam, N. (1996). Effectiveness correlates of transformational and transactional leadership: A meta-analytic review of the MLQ literature. Leadership Quarterly, 7(3), 385-425.

Maher, K. J. (1997). Gender-related stereotypes of transformational and transactional leadership. Sex Roles, 37(3/4), 209-225.

McGrattan, R. J. (1997). The relationship between personality traits and transformational leadership between North Carolina elementary public school principals. Unpublished doctoral dissertation, East Tennessee State University, Johnson City, TN. 
McHugh, K. J. (1999). Exploring the relationship between perceptions of principals' leadership behaviors and potency of teaching teams at the middle level. Unpublished doctoral dissertation, Lehigh University, Bethlehem, PA.

Manning, T. T. (2002). Gender, managerial level, transformational leadership, and work satisfaction. Women in Management Review, 17(5), 207-216.

Oakley, J. G. (2000). Gender-based barriers to senior management positions: Understanding the scarcity of female CEO's. Journal of Business Ethics, 27(4), 321-324.

Rosener, J. (1990, November/December). Ways women lead. Harvard Business Review,119-125.

Rush, M. C., Thomas, J. C., \& Lord, R. G. (1977). Implicit leadership theory: A potential threat to the internal validity of leader behavior questionnaires. Organizational Behavior and Human Performance, 20, 93-110.

Russell, J., Rush, M., \& Herd, A. (1988). An exploration of women's expectations of effective male and female leadership. Sex Roles, 18, 279-287.

Schein, V. E. (2001). A global look at psychological barriers to women's progress in management. Journal of Social Issues, 57(4), 675-688.

van Engen, M. L., van der Leeden, R., \& Willemsen, T. M. (2001). Gender, context, and leadership styles: A field study. Journal of Occupational and Organizational Psychology, 74, 581-598.

Vecchio, R. P. (2002). Leadership and gender advantage. Leadership Quarterly, 13, 643-671. 